\title{
(IN)EXISTÊNCIA DE INDICAÇÃO GEOGRÁFICA AFETA AO COMPLEXO CULTURAL DO BUMBA MEU BOI: RECURSO ENDÓGENO COMO ESTRATÉGIA PARA O DESENVOLVIMENTO LOCAL
}

\author{
André Francisco Cantanhede de Menezes ${ }^{1}$ \\ Jussara Suzi Assis Borges Nasser Ferreira ${ }^{2}$
}

\section{RESUMO}

Objetivou-se neste estudo investigar se o Bumba Meu Boi, na forma praticado no estado do Maranhão, afigura-se como instrumento hábil à concretização do escopo desenvolvimentista a partir do advento de uma indicação geográfica. Trata-se de pesquisa de caráter exploratório, com abordagem qualitativa e delineamento fundado na verificação documental, utilizando-se dialeticidade. Conclui-se que o Complexo Cultural do Bumba Meu Boi do Maranhão se apresenta como recurso endógeno fundado na relação entre o elemento espacial (território) e o elemento humano, a partir de tradições culturais, constituindo em ativo regional intangível a ser utilizado como estratégia de desenvolvimento daquela comunidade.

Palavras-chave: Complexo Cultural do Bumba Meu Boi do Maranhão. Cultura. Desenvolvimento. Indicação geográfica. Recurso endógeno.

\section{(IN)EXISTENCE OF GEOGRAPHICAL INDICATION AFFECTING THE COMPLEXO CULTURAL DO BUMBA MEU BOI: ENDOGENOUS RESOURCE AS A STRATEGY FOR LOCAL DEVELOPMENT}

\begin{abstract}
Under the bias of the interface between culture and development, the objective of this embryonic study was to investigate whether Bumba Meu Boi, in the form practiced in the state of Maranhão, appears as a skillful instrument for the realization of the developmental scope from the advent of an indication geographic. This is exploratory research, with a qualitative approach and design based on documentary verification, using dialecticity, based on the specific case of the Complexo Cultural do Bumba Meu Boi do Maranhão, which is recognized by UNESCO as Intangible Cultural Heritage of Humanity. There was a consensus that the geographical indication can be used as an instrument to promote development, subjecting the characteristics of Bumba Meu Boi do Maranhão to the requirements of Law 9,279/1996 and Normative Instruction 095/2018, from INPI, harvested positive result with the advent of the geographical indication. It is concluded that, overcoming the need to strengthen the social capital inherent in the cultural manifestation and structuring the regulation for the use of the distinctive sign, the Complexo Cultural do Bumba Meu Boi do Maranhão presents itself as an endogenous resource founded on the relationship between the spatial element (

\footnotetext{
${ }^{1}$ Doutorando em Direito pela Universidade de Marília - UNIMAR. Mestre em Gestão e Desenvolvimento Regional pela Universidade de Taubaté - UNITAU. Pós-graduado em Direito Ambiental e Direito e Processo Penal e graduado em Direito pela Faculdade de Imperatriz - FACIMP. Professor universitário na Universidade Estadual do Tocantins - UNITINS. Advogado.E-mail: andrefcmenezes@gmail.com

${ }^{2}$ Doutora em Direito das Relações Sociais pela Pontifícia Universidade Católica de São Paulo - PUC/SP. Mestre em Direito pela Universidade Estadual de Londrina - UEL/PR. Professora permanente do Programa de Mestrado e Doutorado em Direito da Universidade de Marília - UNIMAR e do Programa de Mestrado em Direito e Cidadania da Universidade Paranaense - UNIPAR. Advogada.E-mail: jussara@bflaw.adv.br
} 
territory) and the human element, based on cultural traditions, constituting an intangible regional asset to be used as a development strategy for that community.

Keywords: Complexo Cultural do Bumba Meu Boi do Maranhão. Culture. Development. Geographical indication. Endogenous resource.

\section{INTRODUÇÃO}

O Bumba Meu Boi é a mais tradicional manifestação cultural popular do Estado do Maranhão. Gestada durante todo o ano, atinge seu ápice durante as festividades em honra aos Santos juninos, com destaque para São João, São Pedro e São Marçal. Tem por enredo o furto de um boi, por Francisco, para atender ao desejo de sua esposa, Catirina, que grávida, pretende comer a língua daquele animal. O fazendeiro proprietário do animal, ao saber que o semovente havia sido furtado, confronta Francisco, seu vaqueiro, que há de devolver o boi, sob pena de ser morto. Pajés e curandeiros conseguem ressuscitar o animal que volta à vida urrando. Por conta disso, ao seu redor, há festa para comemorar o milagre.

De fama internacional e com elementos definidores de suas características bem delineados, o Complexo Cultural do Bumba Meu Boi do Estado do Maranhão fora reconhecido, como Patrimônio Cultural Imaterial da Humanidade, pela Organização das Nações Unidas para a Educação, a Ciência e a Cultura-UNESCO.

Frente às características da manifestação cultural em tela, há de ser considerada, então, a perspectiva de potencialização de recursos endógenos para fins de desenvolvimento socioeconômico local, notadamente, por meio de recursos imateriais ligados ao meio geográfico, revestidos de tradição e cultura. Dessa feita, inclina-se a investigar se o Bumba Meu Boi afigura-se como instrumento hábil à concretização daquele escopo a partir do advento de uma indicação geográfica: sinal distintivo que identifica um produto ou serviço que se tenha tornado conhecido por conta, ou da sua área de extração, produção ou fabricação, ou ante as qualidades ou características que lhe são agregadas em decorrência, exclusiva ou essencialmente, do meio geográfico de que se origina.

Tomando-se as precisas definições estabelecidas, em especial, nos artigos 176, 177 e 178, da Lei da Propriedade Industrial, bem ainda, as condições para registro previstas na Instrução Normativa $\mathrm{n}^{\circ}$ 095/2018, do INPI, o problema que lastreia esta pesquisa é materializado no seguinte questionamento: há requisitos materiais para seja o Complexo 
Cultural do Bumba Meu Boi do Estado do Maranhão registrado como indicação geográfica para o fim de instrumentalizar do desenvolvimento socioeconômico local?

Este trabalho é pioneiro em investigar a questão de que ora se cuida. Assim, tem lugar esse objeto de pesquisa, pois, a interação entre um determinado local e os atores que dele fazem parte ou nele têm interesse é pano de fundo para uma série de discussões, sob variados vieses, dentre os quais, destaca-se a temática do desenvolvimento regional. Enquanto processo envolto por múltiplas transformações sociais, econômicas e políticas, por exemplo, ganha destaque esse viés, por estar relacionado com a melhora da vida que se leva e das liberdades que se desfruta (SEN, 2010, p. 23 e 29), localmente, sobretudo, ante o fortalecimento de elementos endógenos. Some-se a isso ser íntima a relação entre indicação geográfica e desenvolvimento regional, pois, a um só tempo, aquele elemento da propriedade intelectual serve como proteção oponível contra usos indevidos, como um potencial gerador de negócios e como instrumentalizador o desenvolvimento regional, segundo Carls (2016, p. 40).

A relevância dessa pesquisa é maximizada, pois, sendo indiscutível a carga cultural e os elementos tradicionais vinculados aos elementos humano e territorial do Maranhão, passados vinte e quatro anos do advento da Lei da Propriedade Industrial, sob a conformação constitucional vigente, segundo dados do Instituto Nacional da Propriedade Industrial-INPI, o Maranhão é um dos quatro estados da federação que não têm, vinculado ao seu território, uma indicação geográfica.

Trata-se de pesquisa de caráter exploratório, com abordagem qualitativa e delineamento fundado na verificação documental. A partir de exemplo consistente no caso concreto do Complexo Cultural do Bumba Meu Boi do Estado do Maranhão, utiliza-se o método dialético de modo a pôr em colidência correntes em sede da temática posta, no que tange à interface entre cultura e desenvolvimento.

Salienta-se, todavia, que aqui não se faz um estudo de caso em si, notadamente, por ausência de elementos comparativos advindos de outro caso paradigma. Em verdade, trata-se de discussão embrionária sobre a potencialidade de a manifestação cultural em referência amoldar-se a uma indicação geográfica, e assim, ser utilizada como recurso endógeno imaterial ligado àquele meio geográfico, apto a ser utilizado como instrumento de tutela da cultura local para fins de desenvolvimento. 
Afora introdução e considerações finais, estruturam a parte textual deste trabalho três capítulos, sendo que no primeiro deles, discorre-se sobre a interface entre a cultura e o desenvolvimento, apontando-se ser aquela, dimensão deste. Ainda neste capítulo, traz-se à baila a questão da necessidade de participação da sociedade na escolha de qual cultura e tradição local se pretende ver preservada face às novidades culturais mercadológicas postas pela globalização. A partir desse eixo de discussão, no segundo capítulo, caracteriza-se o Complexo Cultural do Bumba Meu Boi do Estado do Maranhão. No terceiro capítulo, embrenha-se a investigar se referido recurso endógeno preenche os requisitos para ser registrado como indicação geográfica e, assim, ser útil como ferramenta de desenvolvimento socioeconômico local.

\section{INTERFACE ENTRE CULTURA E DESENVOLVIMENTO}

O desenvolvimento é, nesta República, objetivo fundamental cuja consecução, otimizada, deve ser perseguida de modo a construir uma sociedade livre, justa e solidária e reduzir as desigualdades sociais e regionais. Para seja atingido esse fim, dentre outros fatores (como oportunidades econômicas, garantias de transparência e segurança protetora), relevante se mostram o pleno exercício de liberdades políticas e ainda, a existência de facilidades sociais.

Estas liberdades instrumentais (SEN, 2010, p. 11), refletem um ideal de desenvolvimento e podem orientar a elaboração de políticas públicas. Dentre estas, destaca-se a relacionada ao pleno exercício dos direitos culturais e acesso às fontes da cultura local, mediante apoio e incentivo à valorização e à difusão das manifestações culturais.

Com efeito, a cultura é direito social (art. 215, da Constituição, por exemplo) e, mais ainda, direito humano, tal como estampado no art. $5^{\circ}$, da Declaração Universal sobre a Diversidade Cultural, da Organização das Nações Unidas para a Educação, a Ciência e a Cultura-UNESCO. E, não obstante a vertente jurídica - que, sobremaneira, interessa a este trabalho -, a compreensão do que se denomina cultura deve englobar ainda uma tridimensionalidade: a cidadã, a econômica e a simbólica.

No dizer de Lelis e Lôbo (2016, p 746-750), afetas à cultura estão: as conexões com o cotidiano do indivíduo e de seu grupo social, definindo seu estilo de vida; a ação intencional de se expressar como indivíduo dentro de um grupo social, a capacidade do homem, como ser 
racional, de expressar sua realidade por meio de um sistema de representações ou símbolos; a participação do indivíduo no processo de elaboração e execução dos direitos culturais; e ainda, a aferição de seus resultados econômicos, sua capacidade de gerar emprego, renda, tributos, promover o desenvolvimento sustentável, etc.

Contudo, o hodierno cenário mundial globalizante, ao tempo que propicia interação instantânea, inclusive - entre os povos dos mais longínquos lugares, com trocas culturais de múltiplos vieses, tem, na outra face da moeda, a possibilidade de, a partir dessas mesmas trocas, promover sejam incutidas ameaças às culturas nativas de determinados locais.

Em um exemplo abrangente, Sen (2010, p. 308) sinaliza ser o mundo contemporâneo dominado pelo Ocidente "e, embora a autoridade imperial dos antigos governantes do mundo tenha declinado, o domínio ocidental permanece tão forte como antes - sob alguns aspectos, mais forte do que nunca, especialmente nos aspectos culturais. O sol nunca se põe no império da Coca-Cola e da MTV". De modo mais particularizado às vicissitudes locais, Holanda (2014, p. 35), há muito asseverou que, "trazendo de países distantes nossas formas de convívio, nossas instituições, nossas ideias, e timbrando em manter tudo isso em ambiente muitas vezes desfavorável e hostil, somos ainda hoje uns desterrados em nossa terra”. Assim, se de um lado a revolução da tecnologia da informação põe em rede a sociedade, de outro, pode representar a mitigação da tradição e costumes locais que hão de ceder espaço aos modelos estereotipados impostos, em especial, pelo mercado.

Mas, ao revés do que se possa imaginar numa primeira leitura, não há nada de errado nisso, pois, os elementos humanos, espaciais e até mesmo de poder, são mutáveis. Não obstante, o que se põe em jogo é a privação do poder de escolha de uma sociedade em aceitar ou não, os novos rumos culturais que lhe são trazidos, a impor-lhe uma dependência cultural (FURTADO, 1984, p. 25). Com efeito, incumbe à sociedade como um todo, e não somente aos socialmente privilegiados, a participação na discussão para decisão sobre o que preservar e sobre o que há de desaparecer (SEN, 2010, p. 310).

Ainda segundo esse autor:

[...] cabe à sociedade decidir o que fazer para preservar - se é que deseja preservar os modos de vida antigos, talvez até mesmo a um custo econômico significativo. [...] Não existe a obrigação de conservar todo estilo de vida ultrapassado mesmo a um custo muito alto, porém há a necessidade real - para a justiça social - de que as pessoas possam tomar parte nessas decisões sociais se assim o desejarem (SEN, 2010, p. 310). 
Esse ponto controvertido, sobretudo no contexto do desenvolvimento como liberdade, ganha relevo, haja vista revolver a importância das capacidades elementares dos indivíduos e de suas liberdades, substantivas e instrumentais: sendo o desenvolvimento um processo de expansão de liberdades substantivas interligadas, que tem de estar relacionado com a melhora da vida que se leva e das liberdades que se desfruta (SEN, 2010, p. 23 e 29), não há como se desgarrar, neste processo, das tradições e costumes locais que influenciam a construção do indivíduo como agente. Isso, pois, “a comunicação simbólica entre os seres humanos e o relacionamento entre esses e a natureza, com base na produção (e seu complemento, o consumo), experiência e poder, cristalizam-se ao longo da história em territórios específicos, e assim geram culturas e identidades coletivas" (CASTELLS, 2016, p 72/73).

Cercear o acesso à cultura ou extirpar as tradições culturais nativas de modo abrupto, sem a chancela do povo, mitiga liberdades políticas e facilidades sociais, transmudando-se em verdadeira forma de privação de liberdades. Com efeito, tradando-se de cultura, pertinente a ilustração de Sen (2010, p. 310), no sentido de que "as tradições perdidas podem fazer muita falta. A extinção de antigos modos de vida pode causar angústia e um profundo senso de perda. É um pouco como a extinção de espécies de animais mais antigos”.

Posta está a relevância da dimensão cultural do desenvolvimento (SACHS,1993, p. 37/38). Ou, em outras palavras, há indiscutível interface entre a cultura e o desenvolvimento locais, sendo que a preservação, a manutenção e o estímulo daquela é estruturante para a consecução deste.

Dessa relação há de se extrair políticas públicas, pois:

\footnotetext{
Para superar as dificuldades em relação à necessidade de subordinar a lógica dos meios àquela dos fins, é crucial a organização de uma vontade coletiva na busca da identidade cultural própria. Nesse sentido, a autonomia cultural é essencial e, portanto, a política cultural é elemento estratégico, estruturador da política de desenvolvimento (BOLAÑO, 2015, p. 241).
}

Nessa linha de raciocínio, em que se põe em debate a relação entre cultura e desenvolvimento, e, de modo mais específico, a compreensão da necessidade de preservação de recursos endógenos imateriais ligados ao meio geográfico em que se está inserido (aspecto de valorização cultural), impende analisar o caso paradigma do Complexo Cultural do Bumba Meu Boi do Estado do Maranhão. 


\section{O BUMBA MEU BOI}

O amo canta e balança o maracá, a matraca e pandeiro é que faz tremer o chão, pois, no mês de junho tem o bumba meu boi que é festejado em louvor a São João: uma "herança deixada por nossos avós, hoje cultivada por nós, para compor" a história do Maranhão. Esta paráfrase advém de trecho de uma das toadas ${ }^{3}$ do cancioneiro popular maranhense, cunhada para embalar a mais tradicional manifestação cultural daquele estado: o Bumba Meu Boi.

A partir da lenda de Mãe Catirina e Pai Francisco, esse espetáculo "resgata uma história típica das relações sociais e econômicas da região nordestina durante o período colonial, marcadas pela monocultura, criação extensiva de gado e escravidão", afirma Furlanetto (2010, p. 108). Tem por enredo o furto de um boi, por Francisco, para atender ao desejo de sua esposa, Catirina, que grávida, pretende comer a língua daquele animal. O fazendeiro proprietário do animal, ao saber que o semovente havia sido furtado, confronta Francisco, seu vaqueiro, que há de devolver o boi, sob pena de ser morto. Pajés e curandeiros conseguem ressuscitar o animal que volta à vida urrando. Por conta disso, ao seu redor, há festa para comemorar o milagre.

O Bumba Meu Boi do Maranhão "é celebração na qual se confundem fé, festa e arte, numa mistura de devoção, crenças, mitos, alegria, cores, dança, música, teatro e artesanato, entre outros elementos" (IPHAN, 2011, p. 8), por isso forma um complexo cultural.

Apesar de ser uma manifestação presente em todo Maranhão, tem mais força nos municípios que compõe o centro-norte do estado - donde emanam vários bois, a exemplo dos de Axixá, Morros, Nina Rodrigues, Pindaré, Boi de Maracanã, Boi da Madre Deus e Boi Barrica -, com destaque para baixada maranhense ${ }^{4}$ e, mais ainda, para a própria São Luís, capital do estado do Maranhão, que concentra as maiores e mais organizadas e variadas festas e apresentações. À cidade de São Luís, inclusive, fora atribuída a denominação de Capital Nacional do Bumba Meu Boi, conforme Lei nº 13.851/2019.

\footnotetext{
${ }^{3}$ Trecho da canção "Maranhão, meu tesouro, meu torrão", cuja letra é de composição de Humberto Maracanã, musicada para o Boi de Maracanã.

${ }^{4}$ Essa região de desenvolvimento está localizada na Baixada Maranhense, semidepressão inserida entre a planície fluvial, a planície costeira e o Golfão Maranhense. Esta região é caracterizada por ser uma área de campos alagáveis, tesos, lagos sazonais e perenes, com economia derivada da pecuária extensiva e da pesca principalmente.

Pinheiro, município mais desenvolvido na região é o polo regional (IMESC, 2018, p. 61).
} 
O sotaque é a denominação usada para classificar os diferentes grupos de bois encontrados no estado do Maranhão, a partir de elementos como especificidades de ritmos, personagens, indumentárias, instrumentos, passos e evolução da dança, esclarece Ribeiro (2018, p. 2). Há cinco tipologias de sotaques legitimadas: de zabumba ou Guimarães; da Ilha ou matraca; da baixada ou Pindaré; de Orquestra; e de Cururupu ou costa de mão (RIBEIRO, 2018, p. 2; MARTINS, 2015, p. 2016).

Há um calendário festivo que rege aquela manifestação cultural, enfatiza Martins (2015, p. 16), sendo seu ciclo dividido, em suma, em quatro etapas: os ensaios, o batismo, as apresentações públicas ou brincadas e a morte.

O Sábado de Aleluia marca o início da temporada dos grupos com os primeiros
ensaios, que se estendem até a primeira quinzena do mês de junho, quando ocorrem
os ensaios redondos (brincadeiras). No dia 23 de junho, véspera do Dia de São João,
tradicionalmente acontecem os batismos dos Bois, quando os grupos obtêm a
licença do santo protetor dos Bumbas para as brincadas. A partir desse ritual
católico, adaptado para permitir que os grupos possam brincar, iniciam-se as
apresentações, que se prolongam até o final do mês. De julho a dezembro acontecem
os rituais de morte dos Bois, programados conforme o calendário de cada grupo,
marcando o encerramento do ciclo festivo do Bumba-meu-boi [sic] (IPHAN, 2011,
p. 9).

Destaca-se que, na parte final do mês de junho - após o batismo (do dia 23 para o dia 24), que dá-se em referência à São João - tem-se o período das apresentações, o qual é coroado por dois grandes encontros de grupos de Bumba-meu-boi [sic]: a alvorada na Capela de São Pedro, na Madre Deus, no dia 29; e o desfile da Avenida São Marçal, no João Paulo, no dia 30 (IPHAN, 2011, p. 9).

Retratado em espaços públicos, o Bumba Meu Boi do Maranhão “constitui uma espécie de ópera popular, resultante da união de elementos das culturas europeia, africana e indígena, no qual o boi é a principal figura de representação”, frisa Furlanetto (2010, p. 108). Não obstante haver em vários outros lugares do Brasil e do mundo diversas manifestações culturais, algumas inclusive com culto àquele semovente, é no Maranhão que referido folguedo ganha contornos próprios, atribuindo-lhe singularidade diferenciadora. E isso se deve não ao culto do boi, em si, mas sim, por conta da tradição cultural secular, fruto da interação entre o homem e seu território, que se estabelece. Nesse sentido:

Ainda que existam formas de expressão similares em outros estados brasileiros, no Maranhão, o Bumba meu boi se diferencia por constituir um complexo cultural que 
compreende uma variedade de estilos, multiplicidade de grupos e, principalmente, porque estabelece uma relação intrínseca entre a fé, a festa e a arte, fundamentada na devoção aos santos juninos, nas crenças em divindades de cultos de matriz africana e na cosmogonia e lendas da região. O bem cultural está em acordo com os conceitos da Convenção para a Salvaguarda do Patrimônio Cultural Imaterial da Unesco de 2003 (BRASIL, 2019).

Ante essas características, havida fama internacional e embebido por aspectos sociais, econômicos, políticos e de manutenção do meio ambiente cultural, o Complexo Cultural do Bumba Meu Boi do Maranhão fora reconhecido, em dezembro de 2019, pela Organização das Nações Unidas para a Educação, a Ciência e a Cultura-UNESCO, como Patrimônio Cultural Imaterial da Humanidade. Aduz a UNESCO (2019), que a partir desse reconhecimento:

\footnotetext{
as ações de salvaguarda já desenvolvidas pelas comunidades praticantes do Complexo Cultural do Bumba Meu Boi, em conjunto com o Instituto do Patrimônio Histórico e Artístico Nacional (Iphan) e entidades parceiras, serão reforçadas e buscarão fortalecer a autonomia dos grupos; promover mais ações de educação patrimonial; realizar nova documentação; além de ampliar pesquisas e de promover ainda mais a valorização desse importante bem cultural.
}

Com efeito, a inscrição na lista da Unesco proporcionará ao Bumba Meu Boi “maior visibilidade, contribuindo para reforçar a imagem culturalmente diversificada do Brasil no exterior, como também incentivar a criatividade humana e o respeito à diversidade cultural, sendo um fator a mais de mobilização dos praticantes do Bumba meu boi” (BRASIL, 2019).

Delineado esse cenário, identifica-se o Complexo Cultural do Bumba Meu Boi do Estado do Maranhão como recurso endógeno que pode ser potencializado para constituir ativo regional a ser usado como elemento de estratégia de desenvolvimento socioeconômico local.

\section{BUMBA MEU BOI: (IN)EXISTÊNCIA DE INDICAÇÃO GEOGRÁFICA}

A propriedade intelectual, como ativo intangível consistente em bem imaterial, tutela a capacidade e atividade criacional do gênio humano para que, tanto possa o seu criador dele usufruir como, esse mesmo criador, possa sobre aquele fruto exercer impeditivos a quem indevidamente os queira utilizar.

Considerado esse arranjo, a propriedade intelectual, refere-se, portanto, "em sentido amplo, às criações do espírito humano e aos direitos de proteção dos interesses dos criadores sobre suas criações", segundo Jungmann e Bonetti (2010, p. 19). Com efeito, os “intellectual 
property rights protect the interests of innovators and creators by giving them rights over their creations" (OMPI, 2016, p. 3).

Dentre os institutos da propriedade intelectual, considera-se, ante o escopo deste trabalho, a indicação geográfica. Esta é sinal distintivo que identifica um produto ou serviço que se tenha tornado conhecido por conta, ou da sua área de extração, produção ou fabricação, ou ante as qualidades ou características que lhe são agrega.

Referido elemento da propriedade intelectual tem assento normativo do art. 176 ao art. 182, da Lei da Propriedade Industrial e é estruturado sob duas formas: denominação de origem, ou seja, o nome geográfico de país, cidade, região ou localidade de seu território, que designe produto ou serviço cujas qualidades ou características se devam exclusiva ou essencialmente ao meio geográfico, incluídos fatores naturais e humanos; e, indicação de procedência, a indicar o nome geográfico de país, cidade, região ou localidade de seu território, que se tenha tornado conhecido como centro de extração, produção ou fabricação de determinado produto ou de prestação de determinado serviço.

A indicação geográfica tem múltiplas funções, dentre as quais destacam-se duas, a saber, a de se prestar a tutelar direitos, sobretudo, contra usos indevidos, e a de gerar a possibilidade de exploração comercial do ativo, diz Carls (2016, p. 42). Pode ser utilizada como instrumento para fomentar o processo de desenvolvimento de uma localidade, explica Locatelli (2008, p. 17). Com efeito, pode gerar, por exemplo, benefícios econômicos (demanda, clientela, aviamento), sociais (empregabilidade, mitigação do êxodo, capital social), culturais (valorização de identidades e do território, tradição, sentimento de pertença), ao meio ambiente (por sua preservação e sustentabilidade) e de governança (empoderamento institucional local, arrecadação e cooperação regional).

Volvendo-se ao Bumba Meu Boi, tem-se que essa manifestação cultural é fruto da criatividade humana, e assim, forma um ativo intelectual "passível da apropriação pelo meio produtivo local através dos mecanismos da propriedade intelectual" (DUPIM; HASENCLEVER, 2016, p. 31). Nessa perspectiva desenvolvimentista, interessa saber se o complexo cultural em questão preenche os requisitos materiais para seja registrado como indicação geográfica.

A solver o problema, tem-se que a Lei no 9.279/1996, além de estampar do art. 176 ao art. 182, balizas acerca das indicações geográficas, delega, no parágrafo único, deste último artigo, competência ao INPI para que este, em exercício de poder regulamentar, estabeleça as 
condições de registro daquele signo distintivo. Para cumprir aquele mister, está em vigor a Instrução Normativa no 095/2018, editada por aquela autarquia e que estabelece, em caráter geral, conforme seu preâmbulo, as condições para registro das indicações geográficas com o fim de executar as normas que regulam a propriedade industrial no ponto específico.

Dessa conformação normativa emergem os seguintes requisitos materiais necessários à existência de uma indicação geográfica:

i) haver o produto ou serviço ligado ao nome geográfico e que possa ser descrito e tecnicamente especificado;

ii) existir vínculo entre os sujeitos produtores ou prestadores de serviço com a cadeia do produto ou serviço ligado ao meio geográfico que constitui o sinal distintivo;

iii) haver delimitação a área geográfica de abrangência da indicação;

iv) existir o nome geográfico, ou seja, o nome usado comumente para se referir a um lugar em particular, a uma feição ou a uma área com identidade reconhecida na superfície terrestre $\left(\S 2^{\circ}\right.$, do art. $2^{\circ}$, da IN $n^{\circ}$ 95/2018);

v) inexistir impedimento (cláusula de não-resgistrabilidade) ao nome geográfico (art. 180, da LPI c/c art. 4º da IN n 95/2018);

vi) haver a notoriedade do meio geográfico, que, para fins de indicação de procedência, tornou-se conhecido quando expressamente mencionado, por diferentes fontes, como centro de extração, produção ou fabricação do produto ou de prestação do serviço assinalado $\left(\S 4^{\circ}\right.$, do art. $2^{\circ}$, c/c inciso VI, do art. $7^{\circ}$, da IN n ${ }^{\circ}$ 95/2018), e, para denominação de origem, pois, influente nas qualidades $^{5}$ ou características $^{6}$ do produto ou serviço, incluídos fatores naturais ${ }^{7}$ e humanos ${ }^{8}$ (inciso VI, do art. $7^{\circ}$, da IN no 95/2018); e,

\footnotetext{
${ }^{5}$ Qualidades são os atributos tecnicamente comprováveis e mensuráveis do produto ou serviço, ou de sua cadeia de produção ou de prestação de serviços (inciso III, do $§ 5^{\circ}$, do art. $2^{\circ}$, da IN no 95/2018).

${ }^{6}$ Características são traços ou propriedades inerentes ao produto ou serviço, ou de sua cadeia de produção ou de prestação de serviços (inciso IV, do $\S 5^{\circ}$, do art. $2^{\circ}$, da IN nº 95/2018).

${ }^{7}$ Fatores naturais são os elementos do meio geográfico relacionados ao meio ambiente, como solo, relevo, clima, flora, fauna, entre outros, e que influenciam as qualidades ou características do produto ou serviço (inciso I, do $\S$ $5^{\circ}$, do art. $2^{\circ}$, da IN n ${ }^{\circ} 95 / 2018$ ).
} 
vii) ter presente mecanismos de controle, condições e proibições de uso da indicação geográfica, inclusive, com vislumbre de consequências aos transgressores.

Esses fatores, reunidos simultaneamente, dão azo, em regra, à existência de indicação geográfica. Confrontando-os com o contexto do Complexo Cultural do Bumba Meu Boi do Maranhão, chega-se aos seguintes resultados:

i) $\quad \mathrm{O}$ Bumba Meu Boi é um produto cultural advindo da criatividade humana, fruto da interação do homem com o espaço geográfico que está inserido e como tradição cultural amplamente documentada ao longo dos anos, pode ser descrito e tecnicamente especificado. Amoldase a uma indicação de procedência, pois a tradição no seu fazer, brincar, dançar, expressar, etc., extrapola os cancelos locais e tem renome justamente por conta do nome geográfico de onde provém, o qual se tornou conhecido (alínea “d”, do inciso II, do art. 7º da IN n 95/2018);

ii) Há vínculo entre os sujeitos envolvidos e a cadeia do produto cultural ligado ao meio geográfico que constitui o sinal distintivo, em verdadeiro capital social. Dessa rede entrelaçada, bem definidas são várias as agremiações que celebram a manifestação cultural, os agentes estatais e privados que incentivam a prática e gerenciam seu funcionamento, assim como se tem a teia de consumidores desse produto, os brincantes, simpatizantes e afins;

iii) Possível lançar mão de instrumento oficial para delimitação da área de abrangência (que é o Maranhão) da pretensa indicação geográfica, fazendo-se uso do Sistema Cartográfico Nacional. E neste particular, o trabalho já fora inclusive iniciado com o advento da Lei $\mathrm{n}^{\circ}$ 13.851/2019, que outorgou à cidade de São Luís, a denominação de Capital Nacional do Bumba Meu Boi.

iv) A própria expressão Complexo Cultural do Bumba Meu Boi do Maranhão constitui termo apto a figurar como nome geográfico, não

\footnotetext{
${ }^{8}$ Fatores humanos são os elementos característicos da comunidade produtora ou prestadora do serviço, como o saber-fazer local, incluindo o desenvolvimento, adaptação ou aperfeiçoamento de técnicas próprias (inciso II, do $\S 5^{\circ}$, do art. $2^{\circ}$, da IN $\left.n^{\circ} 95 / 2018\right)$.
} 
incidindo na cláusula de não-resgistrabilidade ao nome geográfico, estampada no art. 180, da LPI e art. $4^{\circ}$, da IN no 95/2018;

v) Há manifesta notoriedade, reconhecida por diferentes fontes, dessa manifestação cultural e de suas peculiares características por conta do local donde se tornou conhecida, sendo a mais relevante delas, a própria atribuição, pela Organização das Nações Unidas-ONU, por meio de sua ramificação UNESCO, da condição de Patrimônio Cultural Imaterial da Humanidade; e,

vi) No que tange a ter presente mecanismos de controle, condições e proibições de uso da indicação geográfica, inclusive, com vislumbre de consequências aos transgressores, em que pese não se ter instrumento normativo único, ainda, sua confecção, para o fim de consecução de indicação geográfica, não reclama demasiados esforços. Pode ser realizado quanto da reunião dos atores locais para efetivamente seja montado o caderno de especificações. E, nessa linha, já há precedente para aparelhar sua confecção, qual seja, as próprias diretrizes que fizeram essa manifestação ser reconhecida como Patrimônio Cultural Imaterial da Humanidade e, mais ainda, as necessárias salvaguardas ${ }^{9}$ exigidas pela UNESCO e necessárias à manutenção daquela condição de patrimônio da humanidade.

Preenchidos, pois, os requisitos da legislação de regência.

Por fim, mesmo que intuitiva a noção de registro de indicação geográfica para produtos de fácil comercialização e, dentre estes, sobretudo os destinados à alimentação (comidas, bebidas, etc.) e ao artesanato, não há de se cogitar não ser possível registrar a referida manifestação cultural como indicação geográfica. O simples fato de ser produto cultural, confere-lhe a resgistrabilidade. E, em verdade, o registro, para o Complexo Cultural do Bumba Meu Boi do Maranhão, como sói a acontecer, teria apenas natureza declaratória, pois, tal qual destacam Fante e Dallabrida (2016, p. 236), "uma vez que implica no reconhecimento de condições pré-existentes, seja da reputação ou da influência do meio

\footnotetext{
${ }^{9}$ Reza o item 3, do art. $2^{\circ}$, da Convenção para Salvaguarda do Patrimônio Cultural Imaterial que: Entende-se por "salvaguarda" as medidas que visam assegurar a viabilidade do patrimônio cultural imaterial, incluindo a identificação, documentação, investigação, preservação, proteção, promoção, valorização, transmissão essencialmente pela educação formal e não formal - e revitalização dos diversos aspectos deste patrimônio (UNESCO, 2003).
} 
geográfico no produto" [sic]. Some-se a isso a lição de Locatelli (2008, p. 243), para quem "a proteção jurídica concedida pela legislação nacional às indicações geográficas prescinde de registro [pois,] o registro é meramente declaratório, existindo o direito mesmo antes do reconhecimento administrativo" (2008, p. 243).

\section{CONSIDERAÇÕES FINAIS}

Sob o viés da interface entre cultura e desenvolvimento, objetivou-se neste embrionário estudo investigar se o Bumba Meu Boi, na forma praticado no estado do Maranhão, afigura-se como instrumento hábil à concretização do escopo desenvolvimentista a partir do advento de uma indicação geográfica. A questão identitária cultural, e sua preservação pelos atores locais, importa a esse processo.

A pesquisa documental revelou, então, que o Bumba Meu Boi do Maranhão, enquanto manifestação cultural secular, é exemplo, a um só tempo: de afirmação da sociedade local em querer preservar essa tradição; de concretização das dimensões cidadã, a econômica e simbólica da cultura local; de resistência às novidades culturais, pondo estas em convivência paralela às já existentes, e não, de modo a se promover dependência cultural; e, da possibilidade de utilização desse recurso endógeno como um produto (cultural) singular ligado ao meio geográfico identificável (Maranhão). Dada a atuação dos atores locais envolvidos, reinventa-se para não só se manter viva, mas também, para alargar seu escopo de abrangência.

Nessa toada, tem-se, à toda evidência, o Complexo Cultural do Bumba Meu Boi do Maranhão como recurso endógeno fundado na relação entre o elemento espacial (território) e o elemento humano, a partir de tradições culturais, o qual pode constituir ativo regional intangível a ser utilizado como estratégia de desenvolvimento daquela comunidade.

Havido o consenso no sentido de que a indicação geográfica pode ser usada como instrumento de fomento do desenvolvimento, ao se submeter as características do Bumba Meu Boi do Maranhão às exigências da Lei $n^{\circ}$ 9.279/1996 e da Instrução Normativa $n^{\circ}$ 095/2018, do INPI, colheu-se resultado positivo. Com efeito, a pesquisa revelou que o Complexo Cultural do Bumba Meu Boi, por preencher os requisitos materiais de regência, amolda-se a uma indicação geográfica sob a forma de indicação de procedência. 
Ele prestaria, sob a forma de propriedade intelectual materializada em indicação geográfica, a tutelar direitos, sobretudo, contra usos indevidos, e a de gerar a possibilidade de exploração comercial do ativo. Neste particular, a manifestação cultural em questão cumpre mais uma dimensão do desenvolvimento, propiciando-se, expansão de liberdades.

Ponto outro a merecer destaque, versa sobre a necessidade de estruturar-se capital social entre os atores envolvidos para levar a adiante a consecução formal dessa indicação geográfica e mais ainda, utilizá-la, concretamente, para o fim do desenvolvimento socioeconômico local, de modo a satisfazer o bem-estar social. Para isso, necessário ainda uniformizar mecanismos de controle, condições e proibições de uso da indicação geográfica, inclusive, com vislumbre de consequências aos transgressores.

Neste particular, como sugestão, trabalhos futuros podem se ocupar a estudar esse ponto controvertido, valendo-se, sobremaneira, das salvaguardas exigidas pela UNESCO e necessárias à manutenção daquela condição de Patrimônio da Humanidade.

\section{REFERÊNCIAS}

BOLAÑO, César Ricardo Siqueira. O conceito de cultura em Celso Furtado. Salvador: EDUFBA, 2015.

BRASIL. Constituição (1988). Constituição da República Federativa do Brasil. Brasília, DF, 05 outubro 1988. Disponível em:

<http://www.planalto.gov.br/ccivil_03/Constituicao/ConstituicaoCompilado.htm> Acesso em: 02 set 2020 .

. Lei $\mathbf{n}^{\circ}$ 9.279, de 14 de maio de 1996. Regula direitos e obrigações relativos à propriedade industrial. Disponível em:

<http://www.planalto.gov.br/ccivil_03/leis/19279.htm>. Acesso em 02 set. 2020.

Lei $\mathbf{n}^{\mathbf{0}}$ 13.851, de 4 de julho de 2019. Denomina a cidade de São Luís, no Estado do Maranhão, Capital Nacional do Bumba Meu Boi. Disponível em: < http://www.planalto.gov.br/ccivil_03/_ato2019-

2022/2019/lei/L13851.htm\#: :text=LEI\%20N\%C2\%BA\%2013.851\%2C\%20DE\%204,Art.>. Acesso em 03 set. 2020.

Ministério do Turismo. Secretaria Especial da Cultura. Complexo Cultural do Bumba meu boi do Maranhão agora é Patrimônio Cultural da Humanidade. 2019. Disponível em: <http://cultura.gov.br/complexo-cultural-do-bumba-meu-boi-do-maranhaoagora-e-patrimonio-cultural-da-humanidade/>. Acesso em 03 set. 2020. 
CARLS, Suelen. Proteção jurídica das indicações geográficas e desenvolvimento: 0 regulamento de uso e as estruturas de controle e gestão. 2016. 217f. Tese (Doutorado em Direito) - Universidade Federal de Santa Catarina, 2016.

CASTELLS, Manuel. A sociedade em rede (a era da informação: economia, sociedade e cultura). vol. 1. Tradução de Roneide Venâncio Majer. 17. ed., rev., atual. São Paulo: Paz e Terra, 2016.

DUPIM, Luiz Claudio de Oliveira; HASENCLEVER, Lia. Indicações geográficas e desenvolvimento local no Brasil: estudo de casos. In: LOCATELLI, Liliana (Org.).

Indicações geográficas: desafios e perspectivas nos 20 anos da lei de propriedade industrial. Rio de Janeiro: Lumen Juris, 2016.

FANTE, Cilmara Correa de Lima; DALLABRIDA, Valdir Roque. Governança territorial em experiências de Indicação Geográfica: análises e prospecções. Desenvolvimento Regional em debate: DRd, v. 6, n. 2, p. 228-246, 2016.

FURLANETTO, Beatriz Helena. O Bumba-meu-boi do Maranhão: território de encontros e representações sociais. Revista RA'EGA - O Espaço Geográfico em Análise, Curitiba, n. 20, p. 107-113, 2010. Editora UFPR.

FURTADO, Celso. Cultura e desenvolvimento em época de crise. Rio de Janeiro: Paz e Terra, 1984.

HOLANDA, Sérgio Buarque de. Raízes do Brasil. 27 ed. São Paulo: Companhia das Letras, 2014.

IMESC - INSTITUTO MARANHENSE DE ESTUDOS SOCIOECONÔMICOS E CARTOGRÁFICOS. Regiões de Desenvolvimento do estado do Maranhão - Proposta Avençada. 2018. Disponível em: <https://seplan.ma.gov.br/files/2013/02/PropostaIMESC_22-Regiões-de-Desenvolvimento-do-Estado-do-Maranhão-2018.pdf >. Acesso em 03 set. 2020.

INPI - INSTITUTO NACIONAL DA PROPRIEDADE INDUSTRIAL. Instrução Normativa $\mathbf{n}^{\circ} \mathbf{9 5}$, de 28 de dezembro de 2018. Estabelece as condições para o registro das Indicações Geográficas. Disponível em:<https://www.gov.br/inpi/pt-br/servicos/indicacoesgeograficas/arquivos/legislacao-ig/INn095de2018. VersoocerizadaparaPortalINPI.pdf $>$. Acesso em 02 set. 2020.

IPHAN - INSTITUTO DO PATRIMÔNIO HISTÓRICO E ARTÍSTICO NACIONAL. Complexo Cultural do Bumba-meu-boi do Maranhão. Dossiê do registro como Patrimônio Cultural do Brasil. 2011. Disponível em:

<http://portal.iphan.gov.br/uploads/ckfinder/arquivos/Dossie_bumba_meu_boi(1).pdf.> Acesso em 03 set. 2020.

JUNGMANN, Diana de Mello; BONETTI, Esther Aquemi. Inovação e propriedade intelectual: guia para o docente. Brasília: Senai, 2010. Disponível em: 
<http://www.inpi.gov.br/sobre/arquivos/guia_docente_iel-senai-e-inpi.pdf >. Acesso em 03 set. 2020 .

LELIS, Henrique Rodrigues; LÔBO, Edilene. A dimensão cultural dos direitos humanos e a efetivação do Estado Democrático de Direito. Revista Jurídica, UniCuritiba, v. 3, n. 44, p. 734-758, Curitiba, 2016.

LOCATELLI, Liliana. Indicações geográficas: a proteção jurídica sob a perspectiva do desenvolvimento econômico. Curitiba: Juruá, 2008.

MARTINS, Carolina Christiane de Souza. Política e cultura nas histórias do Bumba-meuboi: São Luís do Maranhão - Século XX. 2015. 160f. Dissertação (Mestrado em História) Universidade Federal Fluminense, Rio de Janeiro, 2015.

OMPI - ORGANIZAÇÃO MUNDIAL DA PROPRIEDADE INTELECTUAL. Understanding Industrial Property. 2016. Disponível em: <https://www.wipo.int/edocs/pubdocs/en/wipo_pub_895_2016.pdf>. Acesso em: 26 Mar. 2020.

RIBEIRO, Silen. No ritmo do bumba meu boi. Fundação de Amparo à Pesquisa e ao Desenvolvimento Científico e Tecnológico do Maranhão-FAPEMA. 2018. Disponível em: <https://www.fapema.br/index.php/no-ritmo-do-bumba-meu-boi/> Acesso em 03 set. 2020.

SACHS, Ignacy. Estratégias de transição para o século XXI. In: BURSZTYN, M. Para Pensar o Desenvolvimento Sustentável. São Paulo: Brasiliense, 1993.

UNESCO - Organização das Nações Unidas para a Educação, a Ciência e a Cultura. Declaração Universal sobre a Diversidade Cultural. 2002. Disponível em: <http://www.unesco.org/new/fileadmin/MULTIMEDIA/HQ/CLT/diversity/pdf/declaration_c ultural_diversity_pt.pdf> Acesso em 09 set. 2020.

Convenção para Salvaguarda do Patrimônio Cultural Imaterial. 2003.

Disponível em: <https://ich.unesco.org/doc/src/00009-PT-Portugal-PDF.pdf> Acesso em 10 set. 2020.

A excepcionalidade da manifestação que abrange diferentes matrizes culturais brasileiras foi reconhecida por unanimidade pelo Comitê da UNESCO. 2019. Disponível em: <https://pt.unesco.org/news/bumba-meu-boi-do-maranhao-agora-e-patrimonio-culturalimaterial-da-humanidade> Acesso em 03 set. 2020. 